\title{
Oral mannitol in control of fluid balance
}

\author{
A POULTON AND M H WINTERBORN
}

Paediatric Renal Dialysis Unit, East Birmingham Hospital

SUMMARY Oral mannitol $40 \mathrm{~g} / \mathrm{m}^{2}$ was given as $5.5 \%$ and $20 \%$ solutions to six dialysed children. Both solutions caused diarrhoea. Body weight showed no significant change after the $5.5 \%$ solution, which may be used as a 'free drink', but fell by $19.8 \mathrm{~g} / \mathrm{g}$ mannitol after the $20 \%$ solution.

Patients with chronic renal failure treated by dialysis must often restrict their fluid intake. Children find this restriction one of the most difficult aspects of treatment by dialysis, particularly if dialysis was preceded by a phase of polyuria. As a result many children experience episodes of fluid overload, which may have fatal consequences. Fluid removal by dialysis may be slow to begin and we have found that oral administration of $20 \%$ mannitol is effective for the rapid removal of body water through the gastrointestinal tract.

\section{Patients and methods}

Six children aged 9 to 16 participated in the study. Two were on haemodialysis and the other four were on continuous ambulatory peritoneal dialysis (CAPD). All except one were fluid restricted to $300-600 \mathrm{ml}$ daily and all found this difficult to accept. The purpose of the study was explained to the children and consent given by their parents.

Five of the children were admitted for the day and were given a standard dose of mannitol $\left(40 \mathrm{~g} / \mathrm{m}^{2}\right)$, flavoured with orange juice as a $5 \cdot 5 \%$ solution (osmolality $302 \mathrm{mOsm} / \mathrm{l}$ ) on the first occasion and as a $20 \%$ solution (osmolality $1099 \mathrm{mOsm} / \mathrm{l}$ ) on the second, to drink over one hour. The sixth child was given $20 \%$ mannitol therapeutically when he was admitted with fluid overload. Each child was weighed on admission and at discharge, after drainage of dialysis fluid for those children on CAPD. All food and fluids were weighed and all stools and urine collected and weighed. CAPD was continued as usual and the input and output recorded. The weight loss attributable to the mannitol was calculated as the difference between the weights on admission and discharge corrected for insensible loss, food and fluid intake, urine output, and fluid balance from CAPD.

Blood was taken for measurement of sodium, potassium, and magnesium concentrations, osmolality, and packed cell volume on admission and discharge. The packed cell volume was also measured at $30,60,120$, and 240 minutes. The pulse and blood pressure were recorded hourly. The patients went home six hours after taking mannitol, by which time the osmotic diarrhoea was abating. The parents kept a record of the number of stools passed for the rest of the day.

The significance of differences was tested by the Mann-Whitney rank sum test.

\section{Results}

Both solutions of mannitol caused diarrhoea of

Table Effect of treatment with $5 \%$ and $20 \%$ mannitol solutions on weight loss in six patients on dialysis

\begin{tabular}{|c|c|c|c|c|c|c|c|c|}
\hline \multirow{2}{*}{$\begin{array}{l}\text { Case } \\
\text { No }\end{array}$} & \multirow[t]{2}{*}{ Diagnosis } & \multirow{2}{*}{$\begin{array}{l}\text { Body } \\
\text { weight }(\mathrm{kg})\end{array}$} & \multirow[t]{2}{*}{ Dialysis } & \multicolumn{2}{|l|}{ Mannitol } & \multirow{2}{*}{$\begin{array}{l}\text { Weight of } \\
\text { stool }(g)\end{array}$} & \multicolumn{2}{|c|}{ Weight loss } \\
\hline & & & & $\begin{array}{l}\text { Concentration } \\
(\%)\end{array}$ & $\begin{array}{l}\text { Dose } \\
(g)\end{array}$ & & (g) & $(g / k g)$ \\
\hline \multirow[t]{2}{*}{1} & Urethral valves & $30 \cdot 9$ & HD & $5 \cdot 5$ & $41 \cdot 2$ & 675 & 26 & $0 \cdot 84$ \\
\hline & & $30 \cdot 5$ & & 20 & $41 \cdot 2$ & 883 & 126 & $4 \cdot 13$ \\
\hline \multirow[t]{2}{*}{2} & Haemolytic uraemic syndrome & $23 \cdot 1$ & CAPD & $5 \cdot 5$ & $34 \cdot 5$ & 240 & +36 & $+1 \cdot 56$ \\
\hline & & $23 \cdot 0$ & & 20 & $34 \cdot 5$ & 147 & 361 & $15 \cdot 7$ \\
\hline 3 & & $19 \cdot 4$ & & 20 & $30 \cdot 3$ & 602 & 587 & $30 \cdot 3$ \\
\hline \multirow[t]{2}{*}{4} & Henoch-Schönlein nephritis & $33 \cdot 0$ & CAPD & $5 \cdot 5$ & $11 \cdot 6$ & Lost & +100 & $+3 \cdot 03$ \\
\hline & & 33.4 & & 20 & $29 \cdot 4$ & $1234^{*}$ & 737 & $22 \cdot 1$ \\
\hline \multirow[t]{2}{*}{5} & Reflux nephropathy & $26 \cdot 4$ & CAPD & $5 \cdot 5$ & $36 \cdot 2$ & 622 & 380 & $14 \cdot 4$ \\
\hline & & $25 \cdot 0$ & & 20 & $23 \cdot 6$ & 346 & 620 & $24 \cdot 8$ \\
\hline 6 & Urethral valves & $41 \cdot 5$ & HD & 20 & $51 \cdot 6$ & 920 & 1046 & $25 \cdot 2$ \\
\hline
\end{tabular}

*Urine mixed with stool.

$\mathrm{HD}=$ Haemodialysis; $\mathrm{CAPD}=$ continuous ambulatory peritoneal dialysis. 
similar volume that began one to two hours after ingestion. Nausea prevented one patient from taking the full dose of $20 \%$ mannitol and another vomited after taking both solutions. The actual dose retained was calculated after measuring the vomitus. The other patients drank the solution without difficulty. One patient opened her bowels into the toilet so the stool could not be weighed. Others were unable to keep small amounts of urine separate from the stools. All the day patients who retained the full dose of mannitol passed at least one further loose stool at home, so the amounts of stool and the total weight losses are underestimated.

After $20 \%$ mannitol the weight loss was 580 $\pm 315 \mathrm{~g}$ but after the $5.5 \%$ solution was minimal $(96 \pm 196 \mathrm{~g})$ (Table). Weight loss was related to the dose of mannitol given as $20 \%$ solution (median $19 \cdot 8 \mathrm{~g} / \mathrm{g}$ mannitol, range $3 \cdot 1-26 \cdot 3 \mathrm{~g} / \mathrm{g}$ mannitol), but the effect was obscured by case 1 who lost only $126 \mathrm{~g}$ despite passing $883 \mathrm{~g}$ of stool and who may have taken additional unrecorded fluid. The use of $20 \%$ mannitol in case 6 rendered an emergency haemodialysis unnecessary.

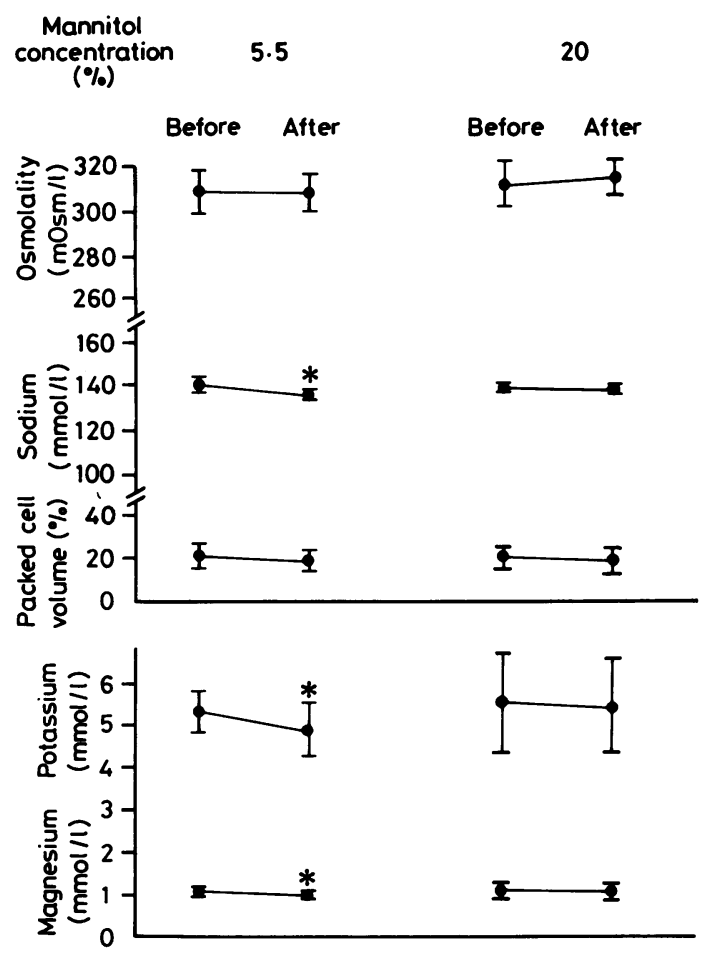

Figure Changes in blood constituents in six patients on dialysis treated by administration of $5 \cdot 5 \%$ and $20 \%$ mannitol, showing mean (SD) values.

${ }^{*} \mathrm{p}<0 \cdot(22$.
After the $5 \cdot 5 \%$ mannitol solution serum electrolyte concentrations, packed cell volume, and osmolality fell significantly but by clinically unimportant amounts (Figure). Blood constituents did not change significantly after $20 \%$ mannitol. Blood pressure and pulse remained stable throughout the study. After the study three patients continued to use $5.5 \%$ mannitol as an unrestricted drink, although they disliked the diarrhoea.

\section{Discussion}

Mannitol $\left(\mathrm{C}_{6} \mathrm{H}_{14} \mathrm{O}_{6}\right)$ is a sugar alcohol that is only partially absorbed from the gastrointestinal tract and causes osmotic diarrhoea. ${ }^{1}$ It tastes about half as sweet as sucrose. Nasrallah and Iber showed that an average of $17.5 \%$ of an oral dose of $20-100 \mathrm{~g}$ mannitol given as a 5\% solution was recovered in the urine. ${ }^{2}$ The absorption depended on the dose given, smaller doses being more completely absorbed. Young et al used a $3 \cdot 28 \%$ solution of mannitol and electrolytes for gastrointestinal dialysis in patients with pre-terminal uraemia. ${ }^{3}$ Seven litres given over three hours resulted in $7 \cdot 2 \%$ absorption of mannitol. Mannitol is partially metabolised, the remainder being excreted in the urine. $^{12}$ Oral mannitol has been used in the treatment of oedema in adults, ${ }^{4}$ but it has not been reported as part of the regular management of fluid balance in chronic renal failure.

Frequent small doses of mannitol might result in considerable absorption of mannitol and water, which would be removed by CAPD but could accumulate in patients on haemodialysis. The small weight loss observed in three patients after $5.5 \%$ mannitol was unexpected but might be explained by loss of faecal material from the bowel. ${ }^{5}$ Chronic administration of $5.5 \%$ mannitol in large quantities might cause appreciable intestinal malabsorption and electrolyte losses. Nevertheless, we think that these possible disadvantages are outweighed by the benefit of improved compliance that results from the availability of a 'free drink' that carries virtually no risk of fluid overload.

Despite the discomfort of profuse diarrhoea we consider that oral $20 \%$ mannitol is a valuable acute treatment for fluid overload in the child with reduced urine output. Mannitol may be given in the home or at school or by the district general paediatrician while arrangements are made to transfer the child for dialysis. Further studies are in progress to define the dose-response relation.

\footnotetext{
References

1 Makinen KK. Effect of long-term peroral administration of sugar alcohols on man. Swed Dent J 1984;8:113-24.
} 
${ }^{2}$ Nasrallah SM, Iber FL. Mannitol absorption and metabolism in man. Am J Med Sci 1969;258:80-8.

3 Young TK, Lee SC, Tai LN. Mannitol absorption and excretion in uraemic patients regularly treated with gastrointestinal perfusion. Nephron 1980:25:112-6.

4 James JW, Evans RA. Use of oral mannitol in the oedematous patient. Br Med $J$ 1970;i:463-5.

5 Donovan IA. Arabi Y, Alexander-Williams J. Modification of the physiological disturbances produced by whole gut irrigation by preliminary mannitol administration. Br J Surg 1980;67: $138-9$.

Correspondence to Dr M H Winterborn, Department of Paediatric Nephrology, East Birmingham Hospital, Bordesley Green East, Birmingham B9 5ST, England.

Received 5 January 1987

\title{
Brain stem glioma presenting as gastro-oesophageal reflux
}

\author{
M J MAHONY, J D KENNEDY, A LEAF, D J MATTHEW, AND P J MILLA \\ Department of Child Health and Respiratory Unit, Institute of Child Health and Hospital for Sick Children, \\ London
}

SUMMARY Brain stem gliomas may present as gastro-oesophageal reflux. In such cases gastrooesophageal reflux presents atypically late, and computed tomography may not detect the presence of the tumour until late in the course of the disease.

Gastro-oesophageal reflux occurs commonly in infants and typically presents with vomiting soon after birth. Respiratory symptoms associated with aspiration, iron deficiency anaemia with oesophagitis, and failure to thrive are, however, well recognised. ${ }^{1}$ Gastro-oesophageal reflux may also occur in a variety of disorders of the central nervous system, including cerebral tumours. In these latter disorders the presentation of reflux is often atypical. We describe here three children with brain stem gliomas who presented initially with gastrooesophageal reflux.

\section{Case reports}

Case 1. A boy was born at term, with a birth weight of $3150 \mathrm{~g}$. At the age of 8 months he started to vomit. Investigations yielded no abnormality on chest or skull $x$-ray film, barium meal and follow through examination, jejunal biopsy, repeated midstream urine specimen examinations, metabolic screening, and computed tomography. Cerebrospinal fluid was xanthochromic, but subsequent carotid angiography yielded normal results. Vomiting continued and at 11 months physical examination revealed brisk knee reflexes only, with weight $5.7 \mathrm{~kg}(<3 \mathrm{rd}$ centile), height $72 \mathrm{~cm}$ (10th centile), and head circumference $44 \mathrm{~cm}$ (3rd centile). A barium meal examination showed a large hiatus hernia with free gastro-oesophageal reflux, and oesophagoscopy showed oesophagitis. A Nissen's fundoplication was performed. After operation the patient developed stridor and signs of a pseudobulbar palsy. Brain scan showed dilatation of the ventricles, with a tumour mass surrounding the fourth ventricle. Despite a ventricular drain, ventilation, and intensive support, the patient's condition continued to deteriorate and he died.

Postmortem examination confirmed the presence of a large tumour, which filled the fourth ventricle and invaded the medulla, pons, and right cerebellar hemisphere. Both the nucleus ambiguus and tractus solitarius were involved. Histology showed a poorly differentiated glioma.

Case 2. A boy was born normally at term, with a birth weight of $3300 \mathrm{~g}$. At the age of 4 months he developed attacks of breath holding, but he thrived otherwise. By 9 months he was vomiting and experiencing paroxysms of coughing. Investigations, including barium meal, oesophagogastroscopy, metabolic studies, electroencephalography (EEG), and computed tomography, yielded normal results. His symptoms continued and by 12 months he presented as a thin, wasted child with persistent drooling, absent ankle reflexes, tongue furrowed on the left side, and his neck held in extension. His weight was $7.65 \mathrm{~kg}$ ( $<3 \mathrm{rd}$ centile), height $72 \mathrm{~cm}$ (3rd centile), and head circumference $46.5 \mathrm{~cm}$ (25th centile). Blood pressure was 110/70. All investigations, including auditory evoked responses, EEG, computed tomography, and those for Riley-Day syndrome, produced normal results except a barium meal examination, which now showed a dilated oesophagus with disordered motility.

Vomiting continued and because of the ineffective and poorly coordinated peristalsis a Nissen's fundoplication and pyloroplasty was performed at 15 